This item was submitted to Loughborough's Research Repository by the author.

Items in Figshare are protected by copyright, with all rights reserved, unless otherwise indicated.

\title{
Wall fluxes of reactive oxygen species of an rf atmospheric-pressure plasma and their dependence on sheath dynamics
}

PLEASE CITE THE PUBLISHED VERSION

http://dx.doi.org/10.1088/0022-3727/45/30/305205

PUBLISHER

(c) IOP Publishing Ltd

\section{VERSION}

AM (Accepted Manuscript)

\section{PUBLISHER STATEMENT}

This work is made available according to the conditions of the Creative Commons Attribution-NonCommercialNoDerivatives 4.0 International (CC BY-NC-ND 4.0) licence. Full details of this licence are available at: https://creativecommons.org/licenses/by-nc-nd/4.0/

\section{LICENCE}

CC BY-NC-ND 4.0

\section{REPOSITORY RECORD}

Liu, Ding-Xin, Aijun Yang, Xiao-Hua Wang, Ming-Zhe Rong, Felipe Iza, and Michael G. Kong. 2019. "Wall Fluxes of Reactive Oxygen Species of an Rf Atmospheric-pressure Plasma and Their Dependence on Sheath Dynamics". figshare. https://hdl.handle.net/2134/16405. 


\title{
Wall fluxes of reactive oxygen species of an rf atmospheric-pressure plasma and their dependence on sheath dynamics
}

\author{
D. X. Liu ${ }^{1}$, A. Yang ${ }^{1}$, X. H. Wang ${ }^{1 *}$, M. Z. Rong ${ }^{1}$, F. Iza ${ }^{2}$ and M. G. Kong ${ }^{1,2^{*}}$ \\ ${ }^{1}$ State Key Lab of Electrical Insulation and Power Equipment, Xi'an Jiaotong University, Xi' an, Shaanxi 710049, P R China \\ ${ }^{2}$ School of Electronic, Electrical and Systems Engineering, Loughborough University, LE11 3TU, UK
}

\begin{abstract}
A radio-frequency (rf) atmospheric-pressure discharge in $\mathrm{He}-\mathrm{O}_{2}$ mixture is studied using a fluid model for its wall fluxes and their dependence on electron and chemical kinetics in the sheath region. It is shown that ground-state $\mathrm{O}, \mathrm{O}_{2}^{+}$and $\mathrm{O}^{-}$are the dominant wall fluxes of neutral species, cations and anions, respectively. Detailed analysis of particle transport shows that wall fluxes are supplied from a boundary layer of $3-300 \mu \mathrm{m}$ immediately next to an electrode, a fraction of the thickness of the sheath region. The width of the boundary layer mirrors the effective excursion distance during lifetime of plasma species, and is a result of much reduced length scale of particle transport at elevated gas pressure. As a result, plasma species supplying their wall fluxes are produced locally within the boundary layer and the chemical composition of the overall wall flux depends critically on spatiotemporal characteristics of electron temperature and density within the sheath. Wall fluxes of cations and ions are found to consist of a train of nanosecond pulses, whereas wall fluxes of neutral species are largely time-invariant.
\end{abstract}

\section{Introduction}

Low-temperature atmospheric-pressure gas discharges, commonly known as cold atmospheric-pressure plasmas (CAPs), have in recent years commanded much interest, due to their vast array of applications in medicine [1][2], polymeric modification [3][4], gas remediation [5], food hygiene [6]-[8], photonics and optics [9]-[11], and space exploration [12]-[14], all unrestricted by a vacuum chamber. While sharing similarities with their lowpressure counterparts, CAPs offer some unique physics [15]-[18], for instance an unusual abundance of energetic electrons ( $\geq 5 \mathrm{eV}$ for up to $50 \%$ population) when the electrode gap is below $500 \mu \mathrm{m}$ [19][20]. Significantly, energetic electrons can enable novel chemical reactions critical to applications that may be inaccessible to lowpressure plasmas. Yet, many of these novel features have so far been established in noble gases [17]-[20] with relatively few exceptions [21]-[25]. Therefore it is largely unknown whether unusual characters of CAP physics hold true in molecular gases and whether they may be translated to unlock the considerable potential of CAPs for practical applications, particularly those that rely on reaction chemistry at or near am bient temperature.

In this paper, physics and chemistry of atmospheric microplasmas with an electrode gap down to $500 \mu \mathrm{m}$ is studied for their influence on wall fluxes of reactive plasma species in an electronegative gas, $\mathrm{O}_{2}$, diluted in helium. A radio-frequency (rf) atmospheric pressure discharge sustained at $13.56 \mathrm{MHz}$ is used here as an example of cold atmospheric plasmas, since sheath dynamics in rf CAPs [16] are at present better understood than those of atmospheric dielectric-barrier discharges at lower frequencies $(<100 \mathrm{kHz})$. Recognizing the current paucity of well-validated diagnostics tools for atmospheric plasmas, a computational approach is employed and this is based on a fluid model [26]-[28] with a full account of relevant reaction chemistry as selected from global models

Authors to whom correspondence should be addressed, xhw@mail.xjtu.edu.cn, m.g.kong@lboro.ac.uk
[29]-[32]. The context of this work is intended to include plasma biosciences in which samples inevitably contain living cells and as such temporal characteristics of how plasma species impact on a sample may become important. With this context, the main objective of this work is to characterize electron heating mechanisms of atmospheric rf microplasmas, their role in sustaining key chemical reactions, their relevance to wall fluxes of charged and neutral plasma species, and temporal features of wall fluxes of neutral and charged plasma species.

\section{Electron heating at constant power density}

The fluid model of $\mathrm{He}-\mathrm{O}_{2}$ rf atmospheric pressure plasmas used here employs 17 particles and 60 chemical reactions between them, selected from detailed global model simulations [29][30]. The 17 particles include the ground-state oxygen atoms (O), excited-state oxygen atoms $\left(\mathrm{O}^{*}\right)$, excited oxygen molecules $\mathrm{O}_{2}{ }^{*}$ (including singlet oxygen), ozone $\left(\mathrm{O}_{3}\right)$, super oxide $\left(\mathrm{O}_{2}\right)$, which are known to be important in biology [33], environmental science [34][35], and surface engineering [4], as well as positive ions $\left(\mathrm{O}_{2}{ }^{+}\right.$and $\left.\mathrm{O}_{4}{ }^{+}\right)$and other negative ions $\left(\mathrm{O}^{-}\right.$and $\mathrm{O}_{3}$ ). The plasma is sustained between two parallel-plate electrodes with a separation gap of $d=0.5-3 \mathrm{~mm}$, and the electrode width is much larger than the electrode gap to allow for a one-dimensional model. It is noted that fluid models may become unreliable with an electrode gap being comparable to or less than the Debye length, which is about $100 \mu \mathrm{m}$ for helium CAPs. To this end, the lower end of the gap size is set nominally at $500 \mu \mathrm{m}$ although fluid simulation for $d=250 \mu \mathrm{m}$ is attempted with results (not shown here) consistent to those for $d=0.5-3 \mathrm{~mm}$.

It is assumed that the gas temperature is $350 \mathrm{~K}$, the electron temperature at the electrodes is $1 \mathrm{eV}$, and the secondary electron emission coefficient is 0.01 . To compare electron heating in different cases, the dissipated power density is fixed at $40 \mathrm{~W} / \mathrm{cm}^{3}$. Here the choice of oxygen as the helium-diluting electronegative gas is 


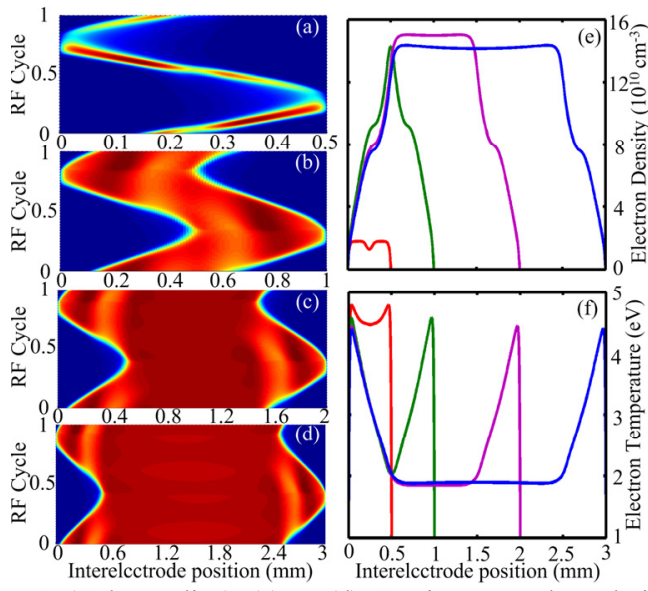

Figure 1 (Color online) (a) - (d) Spatio-temporal evolution of electron density (color is normalized to its maximum in each figure); and spatial profile of time-averaged (e) electron density and (f) electron temperature for an electrode gap of $0.5,1,2$, and $3 \mathrm{~mm}$.

motivated by an increasing evidence of oxidation being a key biological effect in almost all biomedical applications of CAPs [36]-[38], and an $\mathrm{O}_{2} /\left(\mathrm{He}+\mathrm{O}_{2}\right)$ ratio at $0.5 \%$ is based on an optimal condition established experimentally for plasma denaturation of surface proteins [39][40].

Previously rf atmospheric pressure microplasmas have been shown, in pure helium and at constant current density, to acquire abundant energetic electrons when their electrode gap becomes comparable to or less than the sheath thickness [19][20]. To see whether this holds true with the addition of an electronegative gas (and its added electron loss channel via electron attachment) at a constant dissipated power density, figure $1 \mathrm{a}-1 \mathrm{~d}$ show numerically obtained spatio-temporal profiles of electron density. It is clear that plasma bulk becomes diminishing and electrode sheath is severely perturbed when the electrode gap is reduced to $0.5 \mathrm{~mm}$. For $d \geq 1 \mathrm{~mm}$, spatial dependence of the sheath region and its thickness remains very similar, suggesting that the sheath region is largely unperturbed by the varying width of the plasma bulk. This is consistent with rf atmospheric microplasmas in helium [19]. As the electrode gap decreases, the plasma bulk becomes increasingly narrower and eventually negligible, meaning that electrons accelerated in the sheath region would become lost to the instantaneous anode without much further scope to ionize atoms or molecules of the background gas. This suggests large electron temperature $\left(T_{\mathrm{e}}\right)$ but low electron density $\left(n_{\mathrm{e}}\right)$, as it is the case for $d=0.5 \mathrm{~mm}$ in figure 1e and 1f. Only for $d \geq 1$ $\mathrm{mm}$, the plasma bulk is supported with an oscillating central band of electrons (figure $1 \mathrm{~b}$ ). The peak electron density is about $15 \times 10^{10} \mathrm{~cm}^{-3}$ for $d=1-3 \mathrm{~mm}$ (and regardless the gap size) and is about 8 folds of that at $d=$ $0.5 \mathrm{~mm}$. For $d=1-3 \mathrm{~mm}$, time-averaged $T_{\mathrm{e}}$ has two identical peaks near the electrodes, each of $\sim 4.4 \mathrm{eV}$, and its minimum of $\sim 2 \mathrm{eV}$ is found at the center of the electrode gap. At $d=0.5 \mathrm{~mm}$, the spatial profile of $T_{\mathrm{e}}$ is similar but with its maximum at $4.8 \mathrm{eV}$ and its minimum at $4.5 \mathrm{eV}$, both markedly higher than those at larger electrode gaps. It is worth noting that in each rf period $T_{\text {rf }}$ the sheath persists for $\sim 0.8 T_{\text {rf }}$. This is consistent

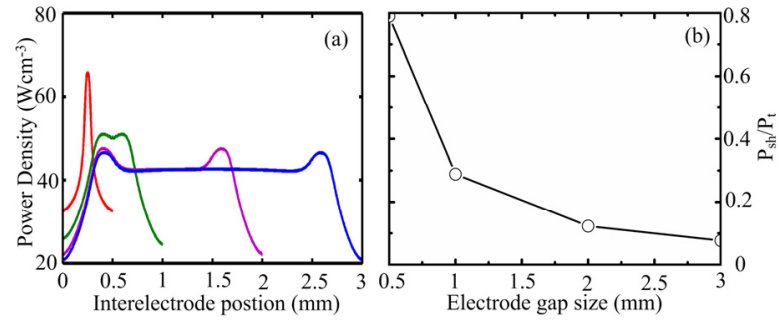

Figure 2 (Color online) Spatial profile of time-averaged dissipated power density and the ratio of the dissipated power in the sheath region $\left(P_{\mathrm{sh}}\right)$ to the total power $\left(P_{\mathrm{t}}\right)$.

with observation in electropositive gases [19].

To see how electron heating may vary with decreasing electrode gap at a constant total dissipated power density, Figure $2 \mathrm{a}$ shows the spatial distribution of the timeaveraged dissipated power density. For cases of $d \geq$ $1 \mathrm{~mm}$, the peak value of the dissipated power density occurs near the edge of each of the two time-averaged sheath regions and its profile within the plasma bulk is largely a plateau. Electric field in the plasma bulk is known to be much smaller than in the sheath, and the dissipated power in the plasma bulk is used largely to maintain the discharge current there [41]. By contrast, the dissipated power in the sheath is used mainly to accelerate electrons and to supply new electrons through ionization. At the constant power density for the entire interelectrode space and with decreasing electrode gap, proportionally more and more dissipated power is spent in the sheath for accelerating electrons. This becomes pronounced for $d<$ $1 \mathrm{~mm}$ when the power dissipated in the sheath region $\left(P_{\mathrm{sh}}\right)$ becomes more than $50 \%$ of the total dissipated power $\left(P_{\mathrm{t}}\right)$ as shown in figure $2 \mathrm{~b}$. At $d=0.5 \mathrm{~mm}$, the plasma bulk is no longer fully formed and the two time-averaged sheath regions start to merge near the center of the electrode gap, leading to the peak power density appearing at the gap center (figure 2a).

For all electrode gaps considered, the decrease of the dissipated power density towards the electrode is caused by wall loss of electrons (figure 2a). The highest of the peak power density is found for the case of $d=0.5 \mathrm{~mm}$, suggesting efficient electron heating. This is consistent with larger $T_{\mathrm{e}}$ at $d=0.5 \mathrm{~mm}$ (figure 1f). Electron density and temperature in figure 1 and the partition of the dissipated power in the sheath and bulk regions in figure 2 combine to illustrate clearly the increasing dominance of electron heating in the sheath region with decreasing electrode gap at constant dissipated power density.

For a given atmospheric pressure gas discharge, the electron density is often correlated to the dissipated power density and as such the dissipated power density is sometimes used as a rough and convenient indicator for application efficiency. Indeed for $\mathrm{rf}$ atmospheric plasmas in electropositive gases [19] and electronegative gases (this work), the time-averaged electron density appears to follow approximately a very similar spatial profile (figure 1e) to that of the dissipated power density (figure 2a) for $d \geq 1 \mathrm{~mm}$. This suggests a similar application efficiency for all cases of $d=1-3 \mathrm{~mm}$. For microplasmas when $d<1 \mathrm{~mm}$ however, whether the 
application efficiency may remain the same becomes much less clear since the electron temperature is now higher but the electron density is lower as shown in figure 1. A further but more important source of uncertainty stems

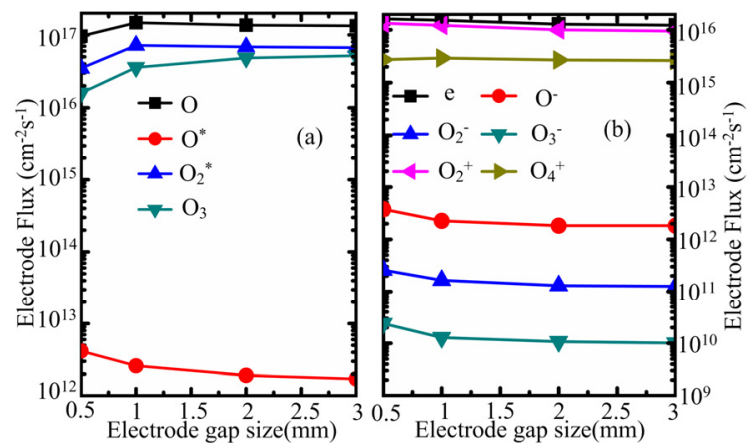

Figure 3 (Color online) Electrode gap dependence of timeaveraged electrode fluxes of (a) neutral plasma species and (b) electron and other charged particles.

from the fact that a sample placed in contact with plasma is likely to have a sheath formed above its surface. The strong electric field in the sheath can in principle form an electrostatic barrier to incoming fluxes of plasma species to the sample, even if there may be plenty relevant plasma species available in the plasma bulk. In other words, the fluxes of plasma species arrived at the sample do not necessarily correlate to their densities in the plasma bulk. It has been known that electrons are significantly trapped in the plasma bulk by the fast oscillating radio-frequency field [42]. It is therefore logical to question whether reactive plasma species generated by trapped electrons are also confined spatially. Conversely it is relevant to question what supplies the fluxes at the sample as electron trapping is increasingly compromised by a shrinking plasma bulk (by decreasing electrode gap). It is clear that plasma species experienced by the sample need to be studied in relation with physics and chemistry in the sheath region.

\section{Wall fluxes of key plasma species}

Since a sheath forms above an electrode or a sample inserted into the plasma, fluxes arriving at one electrode may be used as fluxes arriving at the inserted sample. To this end, wall flux is used here as a general term and is exchangeable in its use with the term of electrode flux. In figure 3, electrode fluxes of neutral and charged particles are shown as a function of the electrode gap. For neutral species, it is evident from figure $3 \mathrm{a}$ that ground-state oxygen atoms have the largest flux at $\Gamma_{\mathrm{O}}=1$ $-1.5 \times 10^{17} \mathrm{~cm}^{-2} \mathrm{~s}^{-1}$, followed by excited oxygen molecules $\left(\Gamma_{\mathrm{O}} / \Gamma_{\mathrm{O} 2} * 2-3\right)$ and ozone $\left(\Gamma_{\mathrm{O}} / \Gamma_{\mathrm{O} 3} \sim 3-6\right)$. By contrast, the flux of excited oxygen atoms is more than four orders of magnitude below that of $\mathrm{O}\left(\Gamma_{\mathrm{O}} / \Gamma_{\mathrm{O}^{*}} \sim 23,000-77,000\right)$. Fluxes of $\mathrm{O}, \mathrm{O}_{2}{ }^{*}$ and $\mathrm{O}_{3}$ follow a similar dependence on the electrode gap with an initial marked increase from $d=$ $0.5 \mathrm{~mm}$ to $1 \mathrm{~mm}$. On the other hand however, the $\mathrm{O}^{*}$ flux decreases monotonically with increasing electrode gap.

In the bulk plasma, the flux of a plasma species is given by $\Gamma_{\mathrm{k}}=n_{\mathrm{k}} v_{\mathrm{k}} / 4$ with $n_{\mathrm{k}}$ and $v_{\mathrm{k}}$ being its concentration and its transport velocity, respectively. Therefore, it is of interest to compare the flux ratios of $\mathrm{O}, \mathrm{O}^{*}, \mathrm{O}_{2}{ }^{*}$ and $\mathrm{O}_{3}$ with their concentration ratios. Our simulation indicates that concentrations of these neutral species changes little with time (data not shown). They reach their peak concentrations in the bulk plasma, from which they decrease monotonically and significantly to the nearest electrode. In other words, the minimum concentration is always found at the electrode. For any given electrode gap, the ratio of the minimum to the maximum concentrations is found to be $n_{\min } / n_{\max }(\mathrm{O})=0.12-0.22$, $n_{\min } / n_{\max }\left(\mathrm{O}_{2}{ }^{*}\right)=0.13-0.25$, and $n_{\min } / n_{\max }\left(\mathrm{O}_{3}\right)=0.17-$ 0.35 , with $n_{\max }$ and $n_{\min }$ being within the same order of magnitude. More relevantly, relative minimum concentrations of $\mathrm{O}_{2}{ }^{*}$ and $\mathrm{O}_{3}$ to $\mathrm{O}$ are found to be comparable to the corresponding relative maximum and the space-averaged concentrations. This indicates a numerical correlation between species concentrations at the electrode to their values elsewhere in the electrode gap. For all electrode gaps, the space-averaged concentration of ground-state oxygen atoms is found to be $n_{\mathrm{O}}=2-7$ $\times 10^{15} \mathrm{~cm}^{-3}$. Its ratios to the concentrations of $\mathrm{O}_{2}{ }^{*}$ and $\mathrm{O}_{3}$ are $n_{\mathrm{O}} / n_{\mathrm{O} 2 *} \sim 2-3$ and $n_{\mathrm{O}} / n_{\mathrm{O} 3} \sim 3-6$, almost identical to their corresponding flux ratios. This close correlation suggests that $\mathrm{O}, \mathrm{O}_{2}{ }^{*}$ and $\mathrm{O}_{3}$ generated in the plasma are transported to an electrode with very similar transportation losses. The relative magnitudes of electrode fluxes are therefore a faithful reflection of their space-averaged concentrations.

By contrast, space-averaged $n_{\mathrm{O}} / n_{\mathrm{O}^{*}}$ is found to be $4,500-5,200$, about half to one order of magnitude below $\Gamma_{\mathrm{O}} / \Gamma_{\mathrm{O}^{*}}$. This means that the conversion of the $\mathrm{O}^{*}$ flux at the electrode from its concentration in the bulk plasma is reduced by a factor of $5-15$ compared to the concentration-flux conversion of the ground-state oxygen atoms. In other words, $\mathrm{O}^{*}$ suffers much greater loss in its transport to an electrode than all other three reactive neutral species. The ratio of the minimum to maximum $\mathrm{O}^{*}$ concentrations is found to be $0.029,0.006,0.005,0.005$ for $d=0.5,1,2,3 \mathrm{~mm}$ respectively. Clearly, the $n_{\min } / n_{\max }\left(\mathrm{O}^{*}\right)$ ratio is not only much smaller than those for any other neutral species but also varies significantly with the electrode gap. This suggests that the space-averaged $\mathrm{O}^{*}$ concentration is not directly correlated to its wall flux.

It is important to recognize that only plasma species with adequate lifetimes could reach the electrode from the plasma region and hence contribute to their wall fluxes. Effective lifetimes of all four neutral oxygen species are found to be $\tau_{\mathrm{O}}=1.1 \mathrm{~ms}, \tau_{\mathrm{O} 2^{*}}=1.25 \mathrm{~ms}, \tau_{\mathrm{O} 3}=1.0 \mathrm{~ms}$ and $\tau_{\mathrm{O}^{*}}=0.5 \mu \mathrm{s}$ estimated from relevant rate coefficients [27] similar to that used previously [43]. Compared to one rf period $\left(T_{\mathrm{rf}}=74 \mathrm{~ns}\right)$, the lifetimes of $\mathrm{O}, \mathrm{O}_{2}{ }^{*}$ and $\mathrm{O}_{3}$ are of the order of 13,500-17,000 rf cycles. This is consistent with simulation results that their concentrations are in fact time invariant, suggesting that once produced they remain fully engaged in underlying chemical reactions. In the case of $\mathrm{O}^{*}, \tau_{\mathrm{O}^{*}}=6.7 T_{\mathrm{rf}}$ is much smaller. This results in small but noticeable variation in the spatial profile of its concentration (data not shown).

To see their influence on wall fluxes, lifetimes of neutral species are used to estimate the excursion distance 
during lifetime (EDL) using $L=\sqrt{D \tau}$ where $D$ is the diffusion coefficient and $\tau$ is the effective lifetime. At 760 torr and $350 \mathrm{~K}$, diffusion coefficients of $\mathrm{O} / \mathrm{O}^{*}, \mathrm{O}_{2}{ }^{*}$ and $\mathrm{O}_{3}$ in helium are estimated to be $0.737,0.644$ and 0.498 $\mathrm{cm}^{2} / \mathrm{s}$, respectively from literature data [44]-[46]. It is

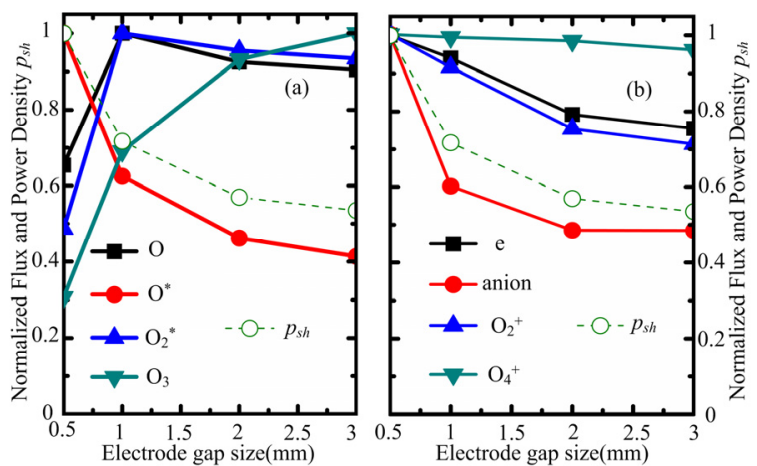

Figure 4 (Color online) Electrode gap dependence of normalized flux and dissipated power density in the sheath region of (a) neutral species and (b) electrons and ions. The anion data are an average with a variation of $\Delta \leq \pm 9 \%$.

found that their EDL are $L_{\mathrm{O}}=285 \mu \mathrm{m}, L_{\mathrm{O} 2 *}=284 \mu \mathrm{m}, L_{\mathrm{O} 3}$ $=223 \mu \mathrm{m}$ and $L_{\mathrm{O}^{*}}=6 \mu \mathrm{m}$. Our simulation data suggest the cathode sheath thickness is $d_{\mathrm{sh}}=472-489 \mu \mathrm{m}$ (increasing with $d$ ), meaning that the EDL of $\mathrm{O}, \mathrm{O}_{2}{ }^{*}$ and $\mathrm{O}_{3}$ are about $46-60 \%$ of the sheath thickness and $L_{\mathrm{O}^{*}} / d_{\mathrm{sh}}$ is only $1.2 \%$. Wall flux of any plasma species is supplied by its generation largely within its EDL from the wall, and the resulting loss of its concentration (in supplying the wall flux) needs to be replenished from its generation outside the EDL. For $\mathrm{O}, \mathrm{O}_{2}{ }^{*}$ and $\mathrm{O}_{3}$, the time invariance in their concentrations and their EDL being a significant fraction of the sheath thickness combine to suggest that their wall losses are likely to be fully replenished. This may be responsible for the close correlation observed between the ratios of their wall fluxes (e.g. $\left.\Gamma_{\mathrm{O}} / \Gamma_{\mathrm{O} 2^{*}}\right)$ to those of their space-averaged concentrations (e.g. $n_{\mathrm{O}} / n_{\mathrm{O} 2 *}$ ). For excited oxygen atoms, their EDL of only $6 \mu \mathrm{m}$ suggests that their replenishment is effective only locally over a very short distance. This difficulty is compounded further by a poor supply of available $\mathrm{O}^{*}$ atoms near an electrode where the $\mathrm{O}^{*}$ concentration is $2-3$ orders of magnitude lower than its value in the plasma bulk. In other words, a highly localized replenishment for the wall loss of $\mathrm{O}^{*}$ and its very low concentration near the wall are the main reasons why $\Gamma_{\mathrm{O}^{*}} / n_{\mathrm{O}^{*}}$ is much smaller than those of $\mathrm{O}$, $\mathrm{O}_{2}{ }^{*}$ and $\mathrm{O}_{3}$.

To see clearly the electrode-gap dependence of all four neutral oxygen species, their electrode fluxes are normalized to their own maximum and plotted in figure 4 with the normalized dissipated power density in the sheath region, $p_{\text {sh }}$. The maximum $p_{\text {sh }}$ is $37 \mathrm{~W} / \mathrm{cm}^{3}$ at $d=0.5 \mathrm{~mm}$. The peak wall flux is found in figure 4 a at $d=1 \mathrm{~mm}$ for $\mathrm{O}$ and $\mathrm{O}_{2}{ }^{*}$, whereas the peak wall flux occurs at $d=0.5 \mathrm{~mm}$ for $\mathrm{O}^{*}$ and at $d=3 \mathrm{~mm}$ for $\mathrm{O}_{3}$. The dominant generation pathway of $\mathrm{O}^{*}$ is $e+\mathrm{O}_{2} \rightarrow \mathrm{O}\left({ }^{1} D\right)+\mathrm{O}+e$ for which the electron energy threshold is $8.6 \mathrm{eV}$. For its wall flux, the electrons involved in the generation of $\mathrm{O}^{*}$ are within its EDL $(\sim 6 \mu \mathrm{m})$ in which $T_{\mathrm{e}}$ changes markedly but $n_{\mathrm{e}}$ remains largely unchanged. These considerations suggest a heightened reliance on energetic electrons. At $d=0.5 \mathrm{~mm}$, the electron temperature is the highest and the availability of more energetic electrons is largely responsible for the larger $\mathrm{O}^{*}$ flux at $d<1 \mathrm{~mm}$ (figure $4 \mathrm{a}$ ). With increasing electrode gap, the space-averaged electron temperature (figure 1f) and the dissipated power density in the sheath decrease with little change in $n_{\mathrm{e}}$ within $\sim 6 \mu \mathrm{m}\left(\right.$ EDL of $\left.{ }^{*}\right)$ from the wall, leading to a deduction in $\Gamma_{\mathrm{O}^{*}}$. Interestingly, $p_{\text {sh }}$ follows a similar electrode-gap dependence to that of the $\mathrm{O}^{*}$ wall flux.

For the generation of $\mathrm{O}, \mathrm{O}_{2}{ }^{*}$ and $\mathrm{O}_{3}$, both electron density and electron temperature are important. $\mathrm{O}$ is generated mainly through $e+\mathrm{O}_{2} \rightarrow 2 \mathrm{O}+e$ (with an electron energy threshold of $5.58 \mathrm{eV})$ and $e+\mathrm{O}_{2} \rightarrow \mathrm{O}\left({ }^{1} D\right)$ $+\mathrm{O}+e$, the latter having a larger reaction rate but a higher electron energy threshold. Different from $\mathrm{O}^{*}$, the EDL of $\mathrm{O}$ is much larger at $285 \mu \mathrm{m}$ and within $285 \mu \mathrm{m}$ from an electrode the increase in $n_{\mathrm{e}}$ is much greater than the reduction in $T_{\mathrm{e}}$ as the electrode gap increases from $d=0.5$ $\mathrm{mm}$ to $1 \mathrm{~mm}$. As a result, the concentration of $\mathrm{O}$ and its wall flux increase. As the gap increases above $1 \mathrm{~mm}$, electron density within the EDL of $\mathrm{O}$ decreases slightly (figure 1e) and electron temperature undergoes a gradual decay (figure 1f). These are responsible for the gradual decay of the $\mathrm{O}$ flux in figure $4 \mathrm{a}$. For $\mathrm{O}_{2}{ }^{*}$ on the other hand, its generation is largely through $e+\mathrm{O}_{2} \rightarrow \mathrm{O}_{2}\left(a^{1} \Delta_{\mathrm{g}}\right)$ $+e$ and $e+\mathrm{O}_{2} \rightarrow \mathrm{O}_{2}\left(b^{1} \sum_{\mathrm{g}}^{+}\right)+e$, requiring low electron energy of $0.977 \mathrm{eV}$ and $1.627 \mathrm{eV}$, respectively. These threshold electron energies are much lower than that for $\mathrm{O}$, hence their generation and their wall fluxes rely more on the electron density, particularly with $\mathrm{O}$ and $\mathrm{O}_{2}{ }^{*}$ having similar EDL. It is therefore not surprising that the $\mathrm{O}_{2}{ }^{*}$ flux and the $\mathrm{O}$ flux share similar dependences on the electrode gap. For $d=1-3 \mathrm{~mm}$, the gradual reduction of $\mathrm{O}$ and $\mathrm{O}_{2}{ }^{*}$ fluxes is consistent with the slight decrease in $n_{\mathrm{e}}$ within $284-285 \mu \mathrm{m}$ (their EDL) from the electrode and with a slight decrease in the electron flux (figure $4 \mathrm{~b}$ ).

Ozone production is through $\mathrm{O}+\mathrm{O}_{2}+\mathrm{He} \rightarrow \mathrm{O}_{3}+\mathrm{He}$ predominantly, thus relying on the $\mathrm{O}$ concentration and hence sharing the dependence of $\mathrm{O}$ on electron density and temperature. Therefore the $\mathrm{O}_{3}$ wall flux increases from $d=0.5 \mathrm{~mm}$ to $1 \mathrm{~mm}$. For $d>1 \mathrm{~mm}$, the ozone flux continues to increase. This can be explained by two $\mathrm{O}_{3}$ loss channels of $\mathrm{O}_{3}+\mathrm{O}_{2}\left(b^{1} \sum_{\mathrm{g}}{ }^{+}\right) \rightarrow 2 \mathrm{O}_{2}+\mathrm{O}$ and $\mathrm{O}_{3}+$ $\mathrm{O}_{2}\left(b^{1} \sum_{\mathrm{g}}{ }^{+}\right) \rightarrow \mathrm{O}_{2}\left(a^{1} \Delta_{\mathrm{g}}\right)+\mathrm{O}_{2}+\mathrm{O}$. As $\mathrm{O}_{2}{ }^{*}$ decreases with increasing electrode gap for $d \geq 1 \mathrm{~mm}, \mathrm{O}_{3}$ loss becomes smaller as the electrode gap increases from $d=1 \mathrm{~mm}$ As a result, the $\mathrm{O}_{3}$ flux increases from $d=1 \mathrm{~mm}$ to $3 \mathrm{~mm}$.

For charged particles, figure $3 \mathrm{~b}$ suggests that electrode fluxes of electrons and positive ions (i.e. $\mathrm{O}_{2}^{+}$and $\mathrm{O}_{4}^{+}$) are much greater than fluxes of negative ions. It has been shown in our previous study that the ambipolar field traps ions in $\mathrm{rf}$ atmospheric plasmas, leading to a central electronegative core and two electropositive edges [28]. Therefore cation concentrations are much larger than anion concentrations in the sheath region. Flux ratios of cations (i.e. $\left.\Gamma_{\mathrm{O} 2+} / \Gamma_{\mathrm{O} 4+}\right)$ and anions (e.g. $\left.\Gamma_{\mathrm{O}-} / \Gamma_{\mathrm{O} 2-}\right)$ are found to correlate numerically to their corresponding concentration ratios (e.g. $n_{\mathrm{O} 2+} / n_{\mathrm{O} 4+}$ and $n_{\mathrm{O}-} / n_{\mathrm{O} 2-}$ ) in the sheath region but not those averaged over the entire electrode gap. To understand this, the drift distance of ions 
is estimated using ion mobility data in ref [27] over a short period during which ion fluxes persist before the electric field reverses its direction of polarity. For cations, they are driven by a strong electric field near the instantaneous cathode and their fluxes persist for $\sim 0.8 T_{\text {rf }}$ (figure $1 \mathrm{a}-$ 1d), suggesting long drift distances. Assuming that the sheath electric field is $\sim 5$ times that of the space-averaged electric field [41], the drift distance is estimated to be $L_{\mathrm{O} 2+}$ $=90-310 \mu \mathrm{m}$ and $L_{\mathrm{O} 4+}=60-200 \mu \mathrm{m}$ with larger drift distance occurring at smaller electrode gap. It is clear that the drift distances of both cations are shorter than the sheath thickness but nonetheless a large fraction of the latter. Similar to $\mathrm{O}, \mathrm{O}_{2}{ }^{*}$ and $\mathrm{O}_{3}$, the large drift distances of $L_{\mathrm{O} 2+}$ and $L_{\mathrm{O} 4+}$ imply that the loss in their concentrations in supplying their wall flux near the instantaneous cathode is likely to be adequately replenished. This is consistent with the numerical correlation between $\Gamma_{\mathrm{O} 2+} / \Gamma_{\mathrm{O} 4+}$ and $n_{\mathrm{O} 2+} / n_{\mathrm{O} 4+}$.

For anions, their fluxes are driven to the instantaneous anode by a rather weak electric field in the anode sheath and their fluxes last for $\sim 0.2 T_{\text {rf }}$ (figure $1 \mathrm{a}-1 \mathrm{~d}$ ). The thickness of the anode sheath is found to be $77-90 \mu \mathrm{m}$ for $d=1-3 \mathrm{~mm}$, whereas the anode sheath is not fully formed for the $d=0.5 \mathrm{~mm}$ case. For $d \geq 1 \mathrm{~mm}$, the thickness of the anode sheath is $16-20 \%$ of that of the cathode sheath, consistent with literature data [47]. Using the space-averaged rms electric field to approximate the anode electric field, the drift distances of anions are found to be $L_{\mathrm{O}-}=5-17 \mu \mathrm{m}, L_{\mathrm{O} 2-}=4-12 \mu \mathrm{m}$ and $L_{\mathrm{O} 3-}=10-33$ $\mu \mathrm{m}$ with larger drift distance found at smaller electrode gap. Clearly these are markedly smaller than the anode sheath thickness, suggesting a compromised facility to replenish species losses in the anode sheath. Noting that anion concentrations are low near electrodes, this suggests that anion wall fluxes are much lower than cation wall fluxes as confirmed in figure $3 \mathrm{~b}$. It should be mentioned that ion drift distances are estimated with approximated electric field near the electrodes. However the general picture remains true in that cations have significantly longer drift distances and more abundant supply to their wall fluxes than anions.

Relative levels of ion fluxes may be understood from key chemical reactions. For cations, generation of $\mathrm{O}_{2}{ }^{+}$is mainly through electron impact ionization $\left(e+\mathrm{O}_{2} \rightarrow \mathrm{O}_{2}^{+}+\right.$ $2 e$ ), whereas that of $\mathrm{O}_{4}^{+}$is via charge transfer from $\mathrm{O}_{2}^{+}$ $\left(\mathrm{O}_{2}^{+}+2 \mathrm{O}_{2} \rightarrow \mathrm{O}_{4}^{+}+\mathrm{O}_{2} ; \mathrm{O}_{2}^{+}+\mathrm{O}_{2}+\mathrm{He} \rightarrow \mathrm{O}_{4}^{+}+\mathrm{He}\right)$. Therefore the concentration and electrode flux of $\mathrm{O}_{2}^{+}$are expected to be higher than those of $\mathrm{O}_{4}^{+}$, as confirmed in figure $3 \mathrm{~b}$. $\quad \mathrm{As}_{2} \mathrm{O}^{+}$production depends on electrons, it is not surprising that the electrode gap dependence of its flux is very similar to the electron flux in figure $4 \mathrm{~b} . \mathrm{O}_{4}^{+}$ production is directly dependent on $\mathrm{O}_{2}$ and $\mathrm{He}$, which do not vary spatially, and its dependence on electrons is indirect via $\mathrm{O}_{2}^{+}$. As a result, the electrode-gap dependence of the $\mathrm{O}_{4}{ }^{+}$flux is rather weak as shown in figure $4 \mathrm{~b}$.

For all anions, their electrode fluxes have very similar dependences on the electrode gap. Generation of $\mathrm{O}^{-}$is mainly via electron impact ionization of $e+\mathrm{O}_{2} \rightarrow \mathrm{O}^{-}+\mathrm{O}$ and $e+\mathrm{O}_{3} \rightarrow \mathrm{O}^{-}+\mathrm{O}_{2}$, so both electron temperature and density are important. Within $L_{\mathrm{O}-}(5-17 \mu \mathrm{m})$ from the instantaneous anode, the rate coefficient of $\mathrm{O}^{-}$generation is found to be $g_{\mathrm{O}-} \sim 10^{-11} \mathrm{~cm}^{3} / \mathrm{s}$. On the other hand, generation of $\mathrm{O}_{2}^{-}$is dominated by $\mathrm{O}_{3}^{-}+\mathrm{O} \rightarrow \mathrm{O}_{2}^{-}+\mathrm{O}_{2}$ in the bulk but by $e+\mathrm{O}_{2}+\mathrm{He} \rightarrow \mathrm{O}_{2}^{-}+\mathrm{He}$ (with a rate of $g_{\mathrm{O} 2-}$ $=10^{-31} \mathrm{~cm}^{6} / \mathrm{s}$ [27]) in the anode sheath where $n_{\mathrm{O} 3} \ll n_{\mathrm{e}}$. It can be shown that $n_{\mathrm{O}-} / n_{\mathrm{O} 2-}=g_{\mathrm{O}-} /\left(g_{\mathrm{O} 2-} n_{\mathrm{He}}\right) \sim 10$ near the

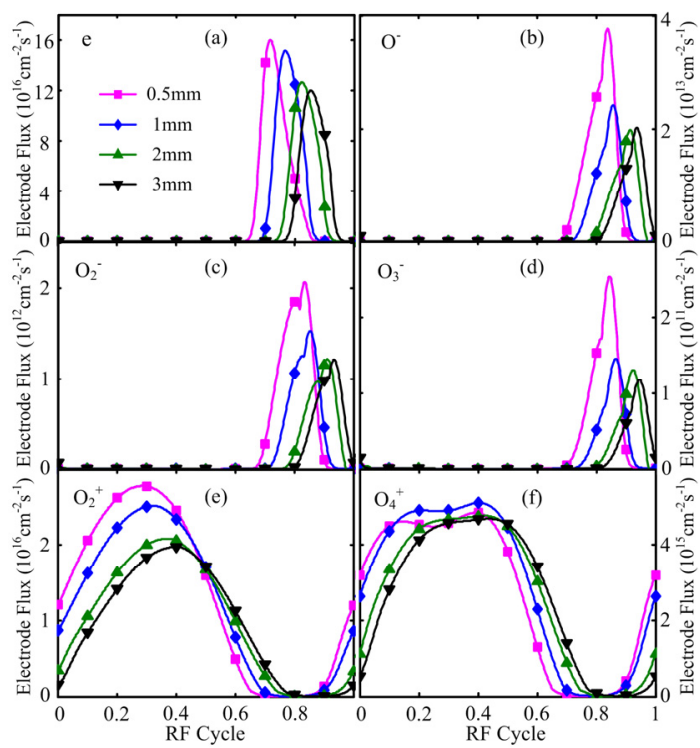

Figure 5 (Color online) Temporal evolution of electrode fluxes of (a) electrons, (b) - (d) anions, and (e) - (f) cations at different electrode gan and $40 \mathrm{~W} / \mathrm{cm}^{3}$.

instantaneous anode. This correlates closely to $\Gamma_{\mathrm{O}} / \Gamma_{\mathrm{O} 2-}=$ 13.7 - 14.6 obtained from figure $3 \mathrm{~b}$. Similarly for $\mathrm{O}_{3}^{-}$ generation, it is mainly via $\mathrm{O}^{-}+\mathrm{O}_{2}+\mathrm{M} \rightarrow \mathrm{O}_{3}^{-}+\mathrm{M}$ with a reaction rate of $g_{\mathrm{O} 3-}=1.1 \times 10^{-30}\left(T_{\mathrm{g}} / 300\right)^{-1}$ [27]. It can be shown that $n_{\mathrm{O} 2-} / n_{\mathrm{O} 3-}=\left(g_{\mathrm{O} 2} n_{\mathrm{e}}\right) /\left(g_{\mathrm{O} 3} n_{\mathrm{O}-}\right) \sim 10$, which correlates well with $\Gamma_{\mathrm{O} 2} / \Gamma_{\mathrm{O} 3-}=10.9-12.9$ in figure $3 \mathrm{~b}$.

From the above discussions, it is clear that both neutral and charged oxygen species contribute to their electrode fluxes only from a narrow space immediately next to an electrode. Essentially an effective excursion distance during lifetime, this narrow space characterizes the length scale over which plasma species can be effectively transported to sustain their wall fluxes and also over which the reduction in their concentrations due to wall loss must be adequately replenished. The EDL is a few tens of micrometers for $\mathrm{O}^{*}$ and anions, and a few hundreds of micrometers for $\mathrm{O}, \mathrm{O}_{2}{ }^{*}, \mathrm{O}_{3}$ and cations. Numerically, it is always shorter than the thickness of the sheath region. This suggests that wall fluxes of plasma species are in general locally supplied and sustained from a boundary layer and therefore their characteristics depend on physics and chemistry in the boundary layer within the sheath region (either the cathode sheath or the anode sheath [48][50]). For long-living neutral species such as $\mathrm{O}, \mathrm{O}_{2}{ }^{*}$ and $\mathrm{O}_{3}$, the time invariance of their concentration allows for their wall fluxes to be correlated numerically to their concentrations averaged over the entire electrode gap distance. This global correlation is numerical and exception to the underlying physics that wall flux phenomena are essentially local. One obvious implication is that CAP source design and process optimization using space-averaged particle concentrations should be approached with caution. 


\section{Temporal characteristics of electrode fluxes}

For non-living materials, temporal features of plasma

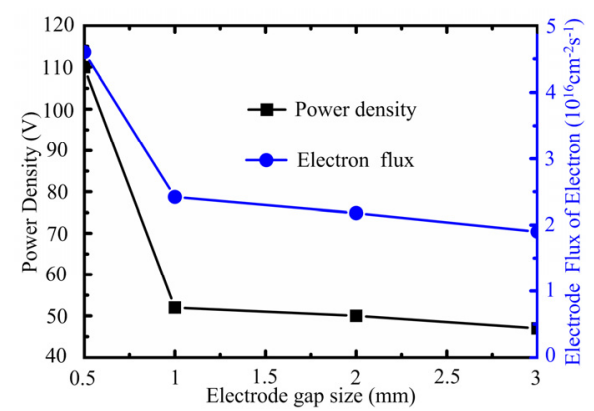

Figure 6 (Color online) Dissipated power density and electron flux at the $\alpha-\gamma$ mode transition point as a function of the electrode gap size.

treatment process are of interest usually only in terms of the total treatment as a measure of plasma dose. For materials containing living cells and tissues, the sequence of different plasma species arriving at a sample may be important. Although global and macroscopic response of a cell or a bacterium may be in a timescale longer than the total plasma treatment time, for example plasma-mediated apoptosis may become apparent many tens of hours after plasma treatment [51], it is known that microscopic dynamics, such as covalent bond breaking of polymeric materials of a cell and their recombination and reformation, may take place at a picosecond scale [25]. To this end, temporal characteristics of electrode fluxes are studied.

Figure 5 shows that electrode fluxes of charged particles have a pulse-like form with the anion and electron pulses. There is one pulse every rf period for any type of charged particle. For cations, their movement towards the instantaneous cathode is driven by the sheath electric field and therefore their pulse is formed during the formation of the sheath above the instantaneous cathode. As the cathode sheath is collapsing and the electrode is evolving to become an instantaneous anode, electrons and anions start to move to the electrode. In other words, the pulses of electrons and negative ions are formed after an electrode becomes an instantaneous anode following the collapsing of the cathode sheath in the previous half $\mathrm{rf}$ cycle. Electron fluxes are larger than cation fluxes in magnitude but narrower in pulse width, exhibiting a distinct temporal asymmetry. Electron pulses are $\sim 0.2 T_{\mathrm{rf}}$ in pulsewidth and cation pulses have a wider pulsewidth of $\sim 0.8 T_{\text {rf }}$. This asymmetry is a result of cation fluxes being driven by a strong sheath electric field lasting for $0.8 T_{\text {rf }}$ and electron fluxes being in a weak anode electric field over a short duration of $\sim 0.2 T_{\text {rf }}$ (figure $1 \mathrm{a}-1 \mathrm{~d}$ ). Due to confinement by the ambipolar field [27], anions are confined in the core of the plasma and this is why anion fluxes are more than 4 orders of magnitude below the wall flux of electrons. Some anions are able to reach the instantaneous anode, as observed with mass spectrometry for an rf atmospheric $\mathrm{He}+\mathrm{H}_{2} \mathrm{O}$ plasma [52].

It is evident from figure 5 that with increasing electrode gap the instant of the maximum instantaneous electron flux is delayed progressively. This is because the sheath thickness increases with increasing electrode gap size and therefore a longer time is needed for electrons in the sheath to reach the instantaneous anode. For $d \geq 1 \mathrm{~mm}$, the pulse width of ions changes little. For neutral species, fluxes of $\mathrm{O}, \mathrm{O}_{2}{ }^{*}$ and $\mathrm{O}_{3}$ vary very little with time and the variation of the $\mathrm{O}^{*}$ flux is at most $10 \%$ within one rf period. Taken together the above discussions, a sample treated by an rf atmospheric $\mathrm{He}+\mathrm{O}_{2}$ plasma is likely to experience a largely time-invariant flux of neutral oxygen species and two alternating pulses of cation and electrons/anion fluxes with asymmetric pulse characteristics. These temporal features are intriguing, even though it is probably premature to speculate their implications to applications.

All results presented above are at a constant power density of $40 \mathrm{~W} / \mathrm{cm}^{3}$. While similar phenomena to those in figure $1-5$ should prevail at different levels of dissipated power density, it is of interest to examine whether 40 $\mathrm{W} / \mathrm{cm}^{3}$ falls within the normal range of operation of $\mathrm{rf}$ atmospheric plasmas. It is known that rf atmosphericpressure discharges tend to become susceptible to plasma instabilities in the so-called $\gamma$ mode at large current densities or large power densities [53][54]. To see whether the results presented may be achieved in the lowcurrent $\alpha$ mode without significant risk of plasma instabilities, the dissipated power density at the $\alpha-\gamma$ mode transition point is computed with the corresponding electron wall flux. Figure 6 shows that the power density at the $\alpha-\gamma$ mode is clearly higher than $40 \mathrm{~W} / \mathrm{cm}^{3}$ at any electrode gap. This suggests that the achievable level of wall fluxes without much risk of plasma instabilities is higher than those predicted in figure 3. In particular, the use of smaller electrode gaps can increase the electron flux to $4.5 \times 10^{16} \mathrm{~cm}^{-2} \mathrm{~s}^{-1}$ from $1.6 \times 10^{16} \mathrm{~cm}^{-2} \mathrm{~s}^{-1}$, a factor of 2.8 . It should be mentioned that significant further increase is feasible as instabilities of rf atmospheric-pressure plasmas in their $\gamma$ mode can be mitigated effectively with the use of dielectric barriers to their electrodes [26], higher excitation frequency [55], and pulse modulation [56].

\section{Concluding remarks}

This study of rf atmospheric-pressure plasmas in an electronegative gas shows that wall fluxes of key plasma species are controlled locally by physics and chemistry in a boundary layer of a few to a few hundreds micrometers next to an electrode, significantly shorter than the length scale of the relevant electrode sheath (i.e. the cathode sheath for neutral species and cations and the anode sheath for anions). In the cathode sheath, electron temperature and density are very different in value to those in the bulk plasma. Their spatial profiles also change drastically over the length scale of the boundary layer and over a characteristic timescale (e.g. lifetime in the case of neutral species). These two aspects highlight a general lack of direct correlation of wall fluxes to corresponding species concentrations either in the plasma bulk or space-averaged. 
This becomes pronounced when the electrode gap size is reduced to, or even below, the thickness of the cathode sheath. A further factor that contributes to the detachment of wall fluxes from global particle transport is the confinement of negative ions by the ambipolar field and their weak acceleration in the anode sheath, both contributing to their concentrations being a much smaller fraction of their values in the plasma bulk than other plasma species. There are exceptions to the above general rule however in the case of long-living neutral species (e.g $\mathrm{O}, \mathrm{O}_{2}{ }^{*}$ and $\mathrm{O}_{3}$ ) whose concentrations are time-invariant over the entire interelectrode space. This time invariance establishes a fixed correlation of their concentrations near an electrode to those at any other location within the electrode gap, thus enabling a numerical, but not physical, correlation to wall fluxes.

In terms of plasma physics, the boundary layer from which to supply wall fluxes stems from effective excursion distance during lifetime (EDL) of plasma species. The numerical value of EDL is strongly affected by diffusion coefficients of neutral species and mobility constants of ions, both scaling inversely with gas pressure [44]-[46][57]. At an elevated pressure including atmospheric pressure, diffusion coefficients and ion mobility constants are much smaller than their values at reduced gas pressure (e.g. millitorr). This suggests that the local reliance of wall fluxes on sheath dynamics in atmospheric-pressure plasmas is a result of much reduced length scale of particle transport at elevated gas pressures, distinctively different from low-pressure discharges whose wall fluxes are likely to be linked to more global particle transport. As the gas pressure increases from millitorrs to atmospheric pressure, particle transport from the plasma bulk to an electrode becomes increasingly ineffective. Eventually, the length scale of particle transport reduces to a fraction of that of an electrode sheath and wall fluxes are now controlled by physics and chemistry in a boundary layer with the electrode sheath. From the standpoint of plasma sources design for practical applications, the above conclusion proposes for a greater focus on phenomena on the plasma-sample interface than those in the plasma bulk. This poses a challenge on diagnostics and their access to the boundary layer, as well as highlights the importance of the material properties and geographical feature of the wall. It is worth noting that the importance of boundary layer in low-temperature atmospheric plasmas has been reported in their effects on self-organization [58], surface modification of diamond and textile materials [59][60], and plasma actuation [61]. It should also be mentioned that boundary-layer physics in near room-temperature atmospheric plasmas are very different from that in atmospheric-pressure arcs [62].

For the rf atmospheric $\mathrm{He}-\mathrm{O}_{2}$ plasma studied here, all charged species reach their peak wall fluxes at $d=0.5 \mathrm{~mm}$ and neutral species reach theirs at $d=1 \mathrm{~mm}$ (for $\mathrm{O}$ and $\left.\mathrm{O}_{2}{ }^{*}\right), d=0.5 \mathrm{~mm}\left(\mathrm{O}^{*}\right)$ and $d=3 \mathrm{~mm}\left(\mathrm{O}_{3}\right)$. Depending on applications, an atmospheric plasma source may be designed to deliver selectively specific plasma species to a sample. Figure 4 indicates a general preference to small electrode gaps (hence to microplasmas) over which the dissipated electric power can be used more directly and more effectively (figure $2 b$ ) to influence the physics and chemistry in the boundary layer. Possible weak supply of plasma species due to small volume of microplasmas [17] may be compensated by using plasma jets [63]-[67] and also arrays of plasma jets [68]. Unlike the spatially diffuse rf atmospheric plasma studied here, plasma jets and plasma-supported streamers [25] have a width scale no more than a few millimeters with a much higher electron density and a narrower sheath $(\sim$ a couple $\mu \mathrm{m}$ in thickness). Although the latter becomes comparable to EDL, the general conclusion should still be true in that electron dynamics and reaction chemistry in the boundary layer are critical for wall fluxes of reactive species.

Considering wall fluxes as a measure of plasma dose, a sample is likely to experience time-invariant dose of neutral species and a string of dose bursts of charged species. Timescales of charged particle bursts are $15 \mathrm{~ns}$ for anions and $60 \mathrm{~ns}$ for cations in the case of the rf atmospheric-pressure plasmas studied here. For polymeric materials including cell membranes and surface proteins, it is unknown whether periodic impact of such nanosecond bursts of charged species may preferentially select some microscopic events involved in, for example, covalent bond modification. However results presented here offer possibilities to explore some intriguing aspects of plasma-material interactions. Indeed, plasma interaction with either abiotic or biotic walls, a currently largely uncharted area in the field of low-temperature plasmas, is likely to need a great deal more in-depth investigations.

\section{Acknowledgement}

This work was supported by the State Key Laboratory of Electrical Insulation and Power Equipment (No. EIPE11108), the Fundamental Research Funds for the Central Universities of China, and the English Department of Health.

\section{References}

[1] Kong M G, Kroesen G, Morfill G, Nosenko T, Shimizu T, van Dijk $\mathrm{J}$ and Zimmermann J L, 2009 Plasma medicine: an introductory review, New J. Phys. 11115012.

[2] Fridman G, Shekhter A B, Vasilets V N, Friedman G, Gutsol A and Fridman A 2008 Applied plasma medicine, Plasma Process. Polym. 5503.

[3] Boyd R D, Kenwright A M and Badyal J P S, 1997 Atmospheric nonequilibrium plasma treatment of biaxially oriented polypropylene, Macromolecules, 305429.

[4] Bhoj A N and Kushner M J 2008, Repetitively pulsed atmospheric pressure discharge treatment of rough polymer surfaces: I. humid air discharges, Plasma Sources Sci. Technol. 17035024.

[5] Kogelschatz, 2003, Dielectric-barrier discharges: their history, discharge physics, and industrial applications, Plasma Chem. Plasma Process. 231

[6] Deng S, Ruan R, Mok C K, Huang G, Lin X and Chen P 2007 Inactivation of $E$. coli on almonds using nonthermal plasma. $J$. Food Sci. 72 M62.

[7] Perni S, Liu D W, Shama G, and Kong M G 2008 Cold atmospheric plasma decontamination of the pericarps of fruit. $J$ Food Protect 71: 302-8.

[8] Perni S, Shama G, and Kong M G 2008 Cold atmospheric plasma disinfection of cut-fruit surfaces contaminated with migrating 
microorganisms. J Food Protect. 711619.

[9] Becker K H, Schoenbach K H and Eden J G 2006, Microplasmas and applications, J. Phys. D. Appl. Phys. 39, R55.

[10] Varault S, Gabard B, Sokoloff J and Bolioli S 2011 Plasma-based localized defect for switchable coupling applications, Appl. Phys. Lett. 98, 134103.

[11] Sakai O and Tachibana K 2012 Plasmas as metamaterials: a review, Plasma Sources Sci. Technol. 21013001.

[12] Latocha V, Garrigues L, Degond P and Bœuf JP 2002 Numerical simulation of electron transport in the channel region of a stationary plasma thruster, Plasma Sources Sci. Technol. 11, 104.

[13] Takao Y and Ono K 2006 A miniature electrothermal thruster using microwave-excited plasmas: a numerical design consideration Plasma Sources Sci. Technol. 15, 211.

[14] West M D, Charles C and Boswell RW 2008 Testing a helicon double layer thruster immersed in a space-simulation chamber $J$. Propulsion Power 24134.

[15] Schenobach K H, El-Habachi, A, Shi W H and Ciocca M 1997 High pressure hollow-cathode discharges Plasma Sources Sci. Technol. 6486.

[16] Shi J J and Kong M G 2005 Mechanisms of the alpha and gamma modes in radio-frequency atmospheric glow discharges, J. Appl. Phys. 97023306.

[17] Eden J G and Park S J 2006 New opportunities for plasma science in nonequilibrium, low-temperature plasmas confined to microcavities: There's plenty of room at the bottom, Phys. Plasma 13057101.

[18] Wang Y H, Zhang Y T, Wang D Z and Kong M G 2007 Period multiplication and chaotic phenomena in atmospheric dielectricbarrier glow discharges, Appl. Phys. Lett. 90071501.

[19] Shi J J and Kong M G 2006 Evolution of discharge structure in capacitive radio-frequency atmospheric microplasmas Phys. Rev. Lett. 96105009

[20] Iza F, Lee J K and Kong M G 2007 Electron kinetics in radiofrequency atmospheric-pressure microplasmas Phys. Rev. Lett. 99, 075004.

[21] Lukes P, Appleton A T and Locke B R 2004 Hydrogen peroxide and ozone formation in hybrid gas-liquid electrical discharge reactors, IEEE Trans. Indus. Appl. 4060.

[22] Walsh J W and Kong M G 200710 ns pulsed atmospheric air plasma for uniform treatment of polymeric surfaces Appl. Phys. Lett. 91251504.

[23] Pai D Z, Stancu G D, Lacoste D A and Laux C O 2009 Plasma Sources Sci. Technol. 18045030

[24] Bruggeman P, Iza F, Guns P, Lauwers D, Kong M G, Gonzalvo, YA; Leys C and Schram D C, 2010 Electronic quenching of OH(A) by water in atmospheric pressure plasmas and its influence on the gas temperature determination by $\mathrm{OH}(\mathrm{A}-\mathrm{X})$ emission, Plasma Sources Sci. Technol. 19015016.

[25] Babaeva N Y, Ning N, Graves D B and Kushner M J, 2012 Ion activation energy delivered to wounds by atmospheric pressure dielectric-barrier discharges: sputtering of lipid-like surfaces, $J$. Phys. D: Appl. Phys. 45115203.

[26] Shi J J, Liu D. W. and Kong M G 2006 Plasma stability control using dielectric barriers in radio-frequency atmospheric pressure glow discharges Appl. Phys. Lett. 89081502.

[27] Yang A, Wang X, Rong M, Liu D, Iza F and Kong M G 2011, 1-D fluid model of atmospheric-pressure $\mathrm{rf} \mathrm{He}+\mathrm{O}_{2}$ cold plasmas: Parametric study and critical evaluation Phys. Plasma 18, 113503.

[28] McKay K, Liu D X, Rong M Z, Iza F, and Kong M G 2011 Dynamics and particle fluxes in atmospheric-pressure electronegative radio frequency microplasmas Appl. Phys. Lett. 99, 091501.

[29] Park G Y, Hong Y J, Lee H W, Sim J Y and Lee J K 2010, A global model for the identification of the dominant reactions for atomic oxygen in $\mathrm{He} / \mathrm{O}_{2}$ atmospheric-pressure plasmas Plasma Process. Polym. 7, 281

[30] Liu D X, Wang X H, Rong M Z, Iza F, Kong M G and Bruggeman
P 2010, Main species and physicochemical processes in cold atmospheric-pressure $\mathrm{He}+\mathrm{O}_{2}$ plasmas, Plasma Process. Polym. 7, 846.

[31] Liu DX, Bruggeman P, Iza F, Rong M Z, Kong M G 2010 Global model of low-temperature atmospheric-pressure $\mathrm{He}+\mathrm{H}_{2} \mathrm{O}$ plasmas Plasma Process. Polymer 19025018.

[32] Liu D X, Iza F, Wang X H, Kong MG and Rong M Z, 2011 $\mathrm{He}+\mathrm{O}_{2}+\mathrm{H}_{2} \mathrm{O}$ plasmas as a source of reactive oxygen species, Appl. Phys. Lett. 98221501.

[33] Halliwell B and Gutteridge J M C, Free Radicals in Biology and Medicine, 4th ed. (Clarendon, Oxford, 2007).

[34] Malik M A, Ghaffar A and Malik S A 2001 Water purification by electrical discharges, Plasma Sources Sci. Technol. 10, 82.

[35] Suzuli T, Saburi T, Tokunami R, Murata H and Fujii Y 2006 Dominant species for oxidation of stainless steel surface in water vapor plasma, Thin Solid Films, 506 - 507, 342.

[36] Deng X, Shi J and Kong M G, 2006 Physical mechanisms of inactivation of Bacillus subtilis spores using cold atmospheric plasmas, IEEE Trans Plasma Sci 341310.

[37] Perni, S, Shama G, Hobman J L, Lund P A, Kershaw C J, Hidalgo-Arroyo G A, Penn C W, Deng X T, Walsh J L, and Kong M G 2007, Probing bactericidal mechanisms induced by cold atmospheric plasmas with Escherichia coli mutants Appl. Phys. Lett. 90, 073902.

[38] Nosenko T, Shimizu T and Morfill G E 2009 Designing plasmas for chronic wound disinfection New J. Phys. 11115013.

[39] Deng X T , Shi J J and Kong M G 2007, Protein destruction by a helium atmospheric pressure glow discharge: Capability and mechanisms J. Appl. Phys. 101074701.

[40] Lee H J, Shon C H, Kim Y S, Kim S, Kim G C and Kong M G, 2009 Degradation of adhesion molecules of G361 melanoma cells by a non-thermal atmospheric pressure microplasma New J. Phys. 11115026.

[41] Shi J J and Kong M G, 2003 Cathode fall characteristics in a dc atmospheric pressure glow discharge J. Appl. Phys. 945504

[42] Liu D W, Shi J J, and Kong M G 2007 Electron trapping in radiofrequency atmospheric-pressure glow discharges Appl. Phys. Lett. 90041502.

[43] Niemi K, Waskoenig J, Sadeghi N, Gans T and O’Connell D 2011 The role of helium metastable states in radio-frequency driven helium-oxygen atmospheric pressure plasma jets: measurement and numerical simulation, Plasma Sources Sci. Technol. 20055005.

[44] Morgan J E and Schiff H I 1964 Diffusion coefficients of O and N atoms in inert gases. Canadian J. Chem. $\mathbf{4 2} 2300$.

[45] Timmins G S, Bechara E J H and Swartz H M 2000 Direct determination of the kinetics of oxygen diffusion to the photocytes of a bioluminescent elaterid larva, measurement of gas- and aqueous-phase diffusional barrier and modeling of oxygen supply. J. Experimental Biology 2032479.

[46] Ivanov A V, Trakhtenberg S, Bertram A K, Gershenzon Y M and Molina M J $2007 \mathrm{OH}, \mathrm{HO}_{2}$, and ozone gases diffusion coefficients, J. Phys. Chem. 1111632.

[47] Farouk T, Farouk B, Staack D, Gutsol A and Fridman A 2006 Simulation of dc atmospheric pressure argon micro glow-discharge, Plasma Sources Sci. Technol., 15, 676.

[48] Langmuir I 1929 The interaction of electron and positive Ion space charges in cathode sheaths, Phys. Rev. 33, 954

[49] Anders A and Anders S 1995 The working principle of the hollowanode plasma source, Plasma Sources Sci. Technol. 4571.

[50] Akishev Y S, Grushin M E, Kochetov I V, Napartovich A P, Pan'kin M V and Trushkin N I 2000 Transition of a multipin negative corona in atmospheric air to a glow discharge, Plasma Phys. Rep. 26 157-163,

[51] Kieft I E, Kurdi M, Stoffels E 2006 Reattachment and apoptosis after plasma-needle treatment of cultured cells, IEEE Trans. Plasma Sci. 341331.

[52] Bruggeman B, Iza F, Lauwers D and Gonzalva Y A 2010 Mass spectrometry study of positive and negative ions in a capacitively 
coupled atmospheric pressure RF excited glow discharge in $\mathrm{He}-$ water mixtures, J. Phys. D: Appl. Phys. 43012003.

[53] Shi J J, Deng X T, Hall R, Punnett J D and Kong M G 2003 Three modes in a radio frequency atmospheric pressure glow discharge $J$. Appl. Phys. 946303.

[54] Yang X, Moravej M, Nowling GR, Babayan SE, Panelon J, Chang J P, and Hicks RF 2005 Comparison of an atmospheric pressure, radio-frequency discharge operating in the alpha and gamma modes Plasma Sources Sci. Technol. 14314.

[55] Shi J J and Kong M G 2005 Expansion of the plasma stability range in radio-frequency atmospheric-pressure glow discharges Appl. Phys. Lett. 87201501.

[56] Balcon N, Aanesland A and Boswell R 2007 Pulsed RF discharges, glow and filamentary mode at atmospheric pressure in argon, Plasma Sources Sci. Technol. 16217.

[57] Ellis H W, McDaniel E W, Albritton D L, Viehland L A, Lin S L and Mason E A 1978 Transport properties of gaseous ions over a wide energy range. Part II. Atom. Data Nucl. Data Tables, 22, 179217.

[58] Schoenbach KH, Moselhy M and Shi WH 2004 Self-organization in cathode boundary layer microdischarges Plasma Sources Sci. Technol. 13 177-185.

[59] Girshick S L, LI C, Yu B W, and Han H 1993 Fluid boundary-layer effects in atmospheric-pressure plasma diamond film deposition, Plasma Process. Plasma Chem. 13 169-187.

[60] Leroux F, Perwuelz A, Campagne C, and Behary N 2006 Atmospheric air-plasma treatments of polyester textile structures $J$. Adhesion Sci. Technol. 20, 939-957.

[61] Font G I 2006 Boundary-layer control with atmospheric plasma discharges AIAA Journal 44 1572-1578.

[62] Schmitz H and Riemann K U 2002 Analysis of the cathodic region of atmospheric pressure discharges J. Phys. D: Appl. Phys. 35 1727-1735.

[63] Walsh J L, Shi J J and Kong MG 2006 Contrasting characteristics of pulsed and sinusoidal cold atmospheric plasma jets Appl. Phys. Lett. 88171501.

[64] Lu XP, Jiang Z H, Xiong Q, Tang Z Y, Hu X W and Pan Y 2008 An $11 \mathrm{~cm}$ long atmospheric pressure cold plasma plume for applications of plasma medicine Appl. Phys. Lett. 92081502.

[65] Bruggeman P, Liu J J, Degroote J, Kong M G, Vierendeels J and Leys C, 2008 DC excited glow discharges in atmospheric pressure air in pin-to-water electrode systems J. Phys. D: Appl. Phys. 41 215201.

[66] Shashurin A, Keidar M, Bronnikov S, Jurjus R A and Stepp M A 2008 Living tissue under treatment of cold plasma atmospheric jet Appl. Phys. Lett. 93181501.

[67] Kolb J F, Mohamed A-A H, Price R O, Swanson R J, Bowman A, Chiavarini R L, Stacey M, and Schoenbach K H 2008 Cold atmospheric pressure air plasma jet for medical applications Appl. Phys. Lett. 92241501.

[68] Cao Z, Walsh J L, and Kong M G 2009, Atmospheric plasma jet array in parallel electric and gas flow fields for three-dimensional surface treatment, Appl. Phys. Lett. 94, 021501. 